\title{
Study on the risk elusion of brand extension in business startups
}

\author{
Yanni Li ${ }^{\text {a }}$, Baichao Gong, Peiyu Li, Zhengpei Chen and Na Guo \\ School of Foreign Languages, Changchun Institute of Technology, Jilin 130012, China; \\ aliyanni2007@163.com
}

Keywords: brand, brand extension, business startups, risk elusion.

\begin{abstract}
Because of the severe competition of business startups, numerous enterprises have realized the importance of the brand, so a lot of enterprises place brand construction and brand protection in an important place. When brand has become famous in the market, how to use brand asset has become a problem that enterprises should take the first consideration. Brand extension is a developing strategy in which an enterprise protects or expands its market share. But brand extension is a two-edged sword. Inappropriate extension cannot help to launch new products or business and may even dilute the core brand. In recent years, many successful enterprises integrate brand asset, adopting brand extension strategy to extend their market. Under this background, it is very important to explore and research brand extension's operating mode and how to evade the risks in brand extension. This paper focuses on the overview of brand and brand extension and points out the meaning of brand extension. It introduces the current operating modes of brand extension and analyzes the condition of brand extension and the principles which affect the enterprises in executing brand extension successfully. The missteps and risks of brand extension are put forward. It will give the enterprises an available reference on how to evade the wrong brand extension.
\end{abstract}

\section{Introduction}

As the development of the economy market, competition has become the main environment of an enterprise's existence and development, especially after the entrance of WTO of China, all the enterprises in China have been facing fierce competition from both domestic and abroad. As the brand of a business is vital to its success, it is of vital importance for an enterprise to lay emphasis on the development, the sales and the creation of brands.

Once a brand has been established, brand marketers are looking for ways to make the best use of this brand asset to expand their portfolios and at the same time decrease the costs of the new products introduced as well as diminish the risk of new products' failure. One of the most popular ways to achieve success is to adopt brand extension strategy. Brand extension, refers to the use of the existing brand name as a vehicle for the new product, enabling it to enter into a completely different (new for the brand) product class [1].

Brand extension has the ability to strengthen and update a brand through addressing new consumer opportunities. However, it is not an easy option that will add incremental sales to a brand. It has considerable potential to undermine the brand's equity if mismanaged. The cases of inappropriate extension are seen everywhere. Haier's failure in PC and medicine, "999" group's failure in "999" beer are the negative examples.

Since brand extension can bring significant benefits for enterprises, it's very important to make a thorough and detail analysis on how to successfully employ this brand extension strategy for Chinese enterprises and evade the risks in execution. This paper gives some constructive suggestions for the operating mode of brand extension in the process of execution and gives some suggestions on how to evade the risks and provides guidance for the enterprises in China.

\section{The Analysis of the Operating Modes and Principles of Brand Extension}

Even though brand extension has considerable risks and limitations, it has become an increasingly adopted method of most enterprises. However, what an enterprise can do is to take full advantages of 
brand extension and choose a proper operating strategy to extend brand. While in executing brand extension, enterprises may face different options of strategies. Each strategy has its own advantages, disadvantages and operating condition. As for the enterprises, only when they grasp these conditions and characteristics, can they execute brand extension successfully.

The operating modes of brand extension

There are many types of operating modes in brand extension, and whether brand extension will succeed mainly depends on which operating mode the enterprises will choose. Like brand line extension, which is so called products line extension. It is the common strategy in brand extension, which refers to the use of an established product's brand name to launch a new, slightly different item in the same product category. New flavors, forms, colors, different ingredients or features, and package sizes are examples of line extensions.

Secondly, brand horizontal extension and brand vertical extension. The former is a marketing strategy of taking the products and services into new industries which refers to introducing the new products under the core brand to the related market. For example, the famous color cosmetics brand Maybelline has produced Maybelline mascara, Maybelline lip gloss, and Maybelline water shine liquid diamonds in succession.

The latter refers to take brands into a seemingly attractive market above or below the current positions. It is the upward extension or down extension in the same industry.

\begin{tabular}{|c|c|c|}
\hline \multirow{2}{*}{ Direction } & $\begin{array}{c}\text { Products introduced to the } \\
\text { market }\end{array}$ & $\begin{array}{c}\text { The extended products in market } \\
\text { expanding }\end{array}$ \\
\hline \multirow{2}{*}{ Upward extension } & Low-quality & Medium/top- quality \\
\cline { 2 - 3 } & Medium- quality & top- quality \\
\hline \multirow{2}{*}{ Down extension } & Low-quality & Low-quality \\
\cline { 2 - 3 } & top- quality & Low/low-quality \\
\hline
\end{tabular}

Generally speaking, upward extension can improve the brand image through extending the products of low quality to a higher quality. While downward extension needs less cost and is simpler to operate, but the company will undertake more risks. By extending the high-quality products to low quality products, the company carries more risks of damaging the core brand.

\section{The risk elusion of brand extension}

Brand extension does have the ability to strengthen and update a brand. However, brand extension is a two-edged sword and is not an easy option that will add incremental sales to a brand. It has considerable potential to undermine the parent brand if a brand extension does not fit with the core brand. Meanwhile, the core brand may not add any value to brand extension products or services resulting in the failure of brand extension. However, brand extension is still a not bad developing strategy and the risk and misstep can be avoided.

Despite there are so many risks and traps in brand extension, it is possible for the enterprises to choose an appropriate strategy and evade the risks while executing brand extension. In this paper, six methods are mentioned.

(1) Defining the brand position accurately and delimiting the application scope

The idea of positioning, first espoused by All Ries and Jack Trout in the 1970's, is how people collectively determine the likelihood of doing business with you. For many brands with a history, the enterprise has made a determined effort to position their business or product favorably and to establish the brand as a unique (differentiated) offering.

As Ries and Trout put it, "they establish a lasting relationship between a positive attribute and the brand in the collective minds of your target market members." That attribute is the differentiator: first, oldest, most innovative, safest, least expensive, sweetest, most versatile, most durable, etc. Products have some sorts of position - whether intended or not. Positions are based upon consumer perceptions, which may or may not reflect reality. A position is effectively built by communicating a 
consistent message to consumers about the product and where it fits into the market - through advertising, brand name, and packaging.

(2) The analysis of the condition of the market competition

In the study of market competition condition, it is necessary to consider both the original products' market and the extended products' market. The enterprise should act according to the intensity of competition in the market to adopt two different extension strategies and avoid "the seesaw" effect occurring [2].

If both of the original products and the extended products are facing very fierce competition in the market, then the execution of brand extension will cause the enterprise in danger. At this moment, the powerful competitors in the two markets possibly can seize the opportunity to launch the attack. When the resources of the enterprise are used dispersedly as well as the consumers hesitate between the two markets, both the original products and the extended products are likely to be damaged.

If the competition in the market of the original products is fierce while in the market of the extended products is weak and meanwhile, the enterprise has an evident competitive advantage in the latter market, then the enterprise should keep the market position of the original products in brand extension. The enterprise should not be relaxed as the success of the extension in the market; otherwise the enterprise is possible to be defeated in the original products' market by its competitor. In addition, one enterprise should not carry on too many brand extensions, which possibly can cause the enterprise's failure for its long battle line.

If the enterprise has had a firm foothold or in the original products' market, while there is fierce competition in the extended products' market, it will be difficult for the enterprise to execute brand extension successfully. An example is Levi's, one of the most widely recognized brands in the history of the apparel industry in America which is famous for its best quality jeans worldwide. With a style for every story, Levi's brings their legendary name to footwear. However, its attempt to launch "Levis for foot" for the development of footwear products market turned out to be a failure. Until now, few people have known about Levi's shoes.

(3) The consistency with the core values and the market positioning with the original product

Successful brand has its own unique core values and characteristics. If this core values and characteristics contain the extension products, brand extension can be successfully executed. In another word, brand extension should take the principle that it must not conflict with the brand original core values. A consistent extension is less likely to change the existing parent brand image.

An irrelevant positioning has the ability to undermine the parent's credentials.

When carrying on brand extension, enterprise should take the core values and characteristics into the first consideration, and then is the connection between the new and old products. It is this intrinsic core values and characteristics explain why so many products with less-connection or even unrelated can be extended successfully.

The similar market position decides the consistency of the products' usage, purchasing target and the manufacture condition which not only conforms to customer's brand association psychology, but also to the actual production of the enterprise [3]. For example, Haier extends its products from refrigerators to air-conditioners, color televisions, washing machines. These extension products all belong to electrical products and are coincident with consumers' impression that Haier is a successful manufacturer of household appliances.

(4) The delivery of meaningful value to the customer

If the value proposition of the brand extension is truly valuable and genuinely meaningful to customers, brand extension opportunities are likely to be unlimited. The products should have a differential advantage in design, which is new, and pleasing to the eye, lower costs or superior perceived quality. Quality here may be in terms of perceived functional benefits or the emotional associations the brand's image conveys. On the other side, only when the extension products have meaningful value that they can sell well in the market.

For example, Virgin can be transferred to new and seemingly unrelated sectors as it is not related directly to one sector successfully, because it has values that can transcend a number of different 
categories. By the same token, Nescafé is a strong brand as it is retained within the overall coffee market but develops added-value sectors such as espresso and cappuccino or premium lines.

(5) The usage of sub-branding strategy

Sub-branding refers to an effort to add an extra name under the parent brand. This strategy is used not just for different products, but for customer segments. If the extension is sub-branded (e.g. Xiaoshentong by Haier) rather than family name (e.g. Haier) less damage will bring to the parent brand. Sub-branding is one managerially controllable factor that permits firms to engage in a more active extension strategy.

The concept of sub-brands is not new, of course. It exists in the extensions of existing products or brands into different product classes, as well as in stretching the brand vertically in its existing product class. Sub-brands may target customers depending on basic socio-demographic and depending on consumer attitude criteria like lifestyle, tastes, needs and interests [4]. They can create different images to different people. However, the sub-brand personalities need to fit the self-expressing needs of the customer. The sub-brand is created in a two-way interaction between customers and firms.

An inferior extension can affect consumers' attitudes toward the parent brands unless a sub-brand was used. The sub-brand serves to insulate the parent brand from the inferior performance of the extension. Therefore, using sub-brand can decrease the risk in extension [5].

\section{Summary}

More and more firms realize that some of their most valuable assets are the brand names associated with their products or services. Creating, maintaining, and enhancing the strength of those brands has become a key management imperative.

One important advantage of having a strong brand is that it can facilitate acceptance of new products launched using that brand name, i.e., brand extensions. Because they reduce consumer risk and significantly lower the cost of introductory marketing programs, brand extensions have become the predominant new product strategy, and the last two decades have seen an explosion in the number of brand extensions. Yet, a large number of brand extensions have been proven to be dismal failures.

It takes years to build equity and loyalty in brands - and a few missteps to destroy them by wrong extension. Thus enterprises should always precede the brand extension with great caution by taking appropriate operating mode and evading risks in brand extension.

\section{Acknowledgements}

The authors would like to give their thanks to The Education Department of Jilin Province (NO. 2015-201) and National Program of Business Startups for University Students for their financial and technical support.

\section{References}

[1]. Aaker, D.A. \& K.L. Keller, Consumer evaluations of brand extensions. Journal of Marketing, 1990, Vol. 54, p 27-41.

[2]. Del I. Hawkins. Consumer Behavior. Mechanic Industry Press, 2006, 8, p.10-11.

[3]. Li Yanni, Li Jiayin, Lv Zheng, Li Tianyu and Tang Yanling. Study of Online Accounts Safety and Online Payments by Smart Phones. Journal of Software Engineering, 2015 9(4), p877-885.

[4]. Li Yanni, Tang Yanling and Gao Shuai. Study on the Current Application of LED products in China. Energy Education Science and Technology Part A: Energy Science and Research, 201432(5), p4259-4264.

[5]. Matt Haig. Brand Failures: The Truth about the 100 Biggest Branding Mistakes of All Time. Beijing: Mechanic Press, 2004, p 30-34. 